\title{
Turismo de Segundas residências no litoral sul do Brasil: uma discussão sobre seu dimensionamento e relevância para a atividade turística contemporânea
}

\author{
Second homes Tourism in the south coast of Brazil: a discussion \\ about its dimension and relevance for contemporary tourism activity
}

\author{
Turismo de Segundas residencias en el litoral sur de Brasil: una \\ discusión sobre su dimensionamiento y relevancia para la actividad \\ turística contemporánea
}

\author{
Cinthia Sena Abrahão ${ }^{1}$ \\ Edegar Luis Tomazzoni
}

Resumo: $O$ objetivo deste artigo consiste em analisar a dimensão da segunda residência turística litorânea na região Sul do Brasil, considerando a premissa de que esse fenômeno persiste relevante no âmbito da atividade turística, tanto em nível internacional, como nacional. Compreende-se a segunda residência como uma tipologia não hoteleira de hospedagem turística, na qual existe um vínculo permanente, mas cuja permanência não exceda ao período de um ano. Aspecto particular refere-se à sua vinculação com as atividades de construção civil, bem como do mercado imobiliário. Problematiza-se a relativa invisibilidade do fenômeno da segunda residência nas bases de dados que subsidiam a elaboração das políticas públicas e ações relativas ao turismo, tanto no âmbito nacional, como nos estados. Em termos de metodologia, a abordagem do tema nesse recorte foi quantitativa e de caráter exploratório. A perspectiva exploratória guiou a revisão bibliográfica, com vistas a compreender a política pública de desenvolvimento turístico e suas prioridades, bem como discutir o fenômeno da segunda residência turística e a forma pela qual tem sido abordado. A análise dos dados secundários envolveu coleta, sistematização e interpretação, tendo em vista explicitar a participação e o crescimento do volume de segundas residências litorâneas. Os dados foram coletados, exclusivamente, para os municípios litorâneos, dos três estados da região sul brasileira nas bases do IBGE. Em seguida foram analisados em processo comparativo dados relativos ao mapa do turismo, no qual os destinos turísticos são classificados. Os resultados reiteram que a desconsideração desses fluxos e dessas dinâmicas territoriais no âmbito da política pública de turismo tende a gerar fortes distorções no planejamento, na sua implementação e nos resultados que poderão ser obtidos.

\footnotetext{
${ }^{1}$ Universidade Federal do Paraná, Matinhos, PR, Brasil. Todos os autores contribuíram em todas as etapas da pesquisa.

2 Universidade de São Paulo, São Paulo, SP, Brasil. Todos os autores contribuíram em todas as etapas da pesquisa.
}

Artigo recebido em: 17/06/2017. Artigo aprovado em: 04/12/2017. 
Entende-se que sua apreensão, no entanto, requer um esforço de levantamento, sistematização e análise estatística distinto daquele que deve ser empreendido para mensurar os fluxos econômicos advindos dos estabelecimentos empresariais relacionados a hospedagem.

Palavras-chave: Turismo. Segunda Residência Turística. Políticas Públicas. Região Sul. Brasil.

Abstract: The objective of this article is to analyze the dimension of the second coastal tourist home in the southern region of Brazil, considering the premise that this phenomenon persists relevant in the scope of tourism activity, both internationally and nationally. The second home is understood as a non-hotel type of tourist accommodation, in which there is a permanent bond, but whose permanence does not exceed the period of one year. Particular aspect refers to its connection with the civil construction activities as well as the real estate market. The relative invisibility of the phenomenon of second residence in the databases that subsidize the elaboration of public policies and actions related to tourism, both at the national level and in the states, is problematic. In terms of methodology, the approach of the theme in this clipping was quantitative and exploratory in nature. The exploratory perspective guided the literature review, with a view to understanding the public policy of tourism development and its priorities, as well as discussing the phenomenon of the second tourist residence and the way in which it has been approached. The analysis of the secondary data involved collection, systematization and interpretation, in order to make explicit the participation and the growth of the volume of second residences of the coast. Data were collected exclusively for the coastal municipalities of the three southern Brazilian states at the IBGE bases. Then, comparative data were analyzed regarding the tourism map, in which the tourist destinations are classified. The results reiterate that the disregard of these flows and territorial dynamics in the context of tourism public policy tends to generate strong distortions in the planning, implementation and results that can be obtained. It is understood that their apprehension, however, requires an effort of surveying, systematization and statistical analysis different from that which must be undertaken to measure the economic flows coming from the business establishments related to lodging.

Keywords: Tourism. Second home tourism. Public Policy. South region. Brazil.

Resumen: El objetivo de este artículo consiste en analizar la dimensión de la segunda residencia turística costera en la región Sur de Brasil, considerando la premisa de que ese fenómeno persiste relevante en el ámbito de la actividad turística, tanto a nivel internacional, como nacional. Se entiende la segunda residencia como una tipología no hotelera de alojamiento turístico, en que existe un vínculo permanente, pero cuya permanencia no excede al período de un año. El aspecto particular se refiere a su vinculación con las actividades de construcción civil, así como del mercado inmobiliario. Se plantea la relativa invisibilidad del fenómeno de la segunda residencia en las bases de datos que subsidian la elaboración de las políticas públicas y acciones relativas al turismo, tanto a nivel nacional, como en los estados. En términos de metodología, el abordaje del tema en ese recorte fue cuantitativo y de carácter exploratorio. La perspectiva exploratoria guió la revisión bibliográfica, con miras a comprender la política pública de desarrollo turístico y sus prioridades, así como discutir el fenómeno de la segunda residencia turística y la forma en que se ha abordado. El análisis de los datos secundarios involucró colecta, sistematización e interpretación, con el fin de explicitar la participación y el crecimiento del volumen de segundas residencias costeras. Los datos fueron levantados exclusivamente para los municipios costeros, de los tres estados de la región sur brasileña, en las bases del IBGE. A continuación, se analizaron en proceso comparativo datos relativos al mapa del turismo, en el que se clasifican los destinos turísticos. Los resultados reiteran que la desconsideración de esos flujos y de esas dinámicas territoriales en el ámbito de la política pública de turismo tiende a generar fuertes distorsiones en la planificación, en su implementación y en los resultados que pueden obtenerse. Se entiende que su aprehensión, sin embargo, requiere un esfuerzo de levantamiento, sistematización y análisis estadístico distinto de aquel que debe ser emprendido para medir los flujos económicos provenientes de los establecimientos empresariales relacionados con el hospedaje.

Palabras clave: Turismo. Segunda Residencia Turística. Políticas públicas. Región sur. Brasil. 


\section{INTRODUÇÃO}

O objetivo deste artigo é analisar a dimensão da segunda residência turística litorânea na região Sul do Brasil, considerando que esse fenômeno, mesmo que relevante no âmbito da atividade turística, tanto em nível internacional, como nacional, não é contemplado por nenhuma política pública de turismo no Brasil. Entende-se que, na sociedade moderna, este espaço privado de lazer e de fruição tornou-se difundido como uma condição do status, particularmente, desde o século XIX. Desde então, ocorreu um processo de massificação, e mais recentemente, tais fluxos se associaram com aqueles que são relativos às novas formas de mobilidade contemporâneas.

Compreende-se a segunda residência como uma tipologia não hoteleira de hospedagem turística, na qual existe um vínculo permanente, pelo retorno sucessivo ao mesmo destino, mas cuja permanência não excede ao período de um ano. Aspecto particular é que, nela, as atividades de construção civil, bem como a de locação de imóveis tornam-se parte dessa modalidade turística (Karayiannis, lakoviou \& Tsartas, 2013; Vágner, Fiolová, 2011).

Desde os anos 2000, o reconhecimento do peso econômico da atividade turística no Brasil promoveu a densificação da estrutura institucional, cujo marco foi a criação do Ministério do Turismo em 2003. Todavia, sua apreensão estatística ainda é consideravelmente precária e incapaz de traduzir para a sociedade a magnitude e os resultados dos fluxos gerados e seus efeitos multiplicadores. As bases oficiais de dados adotam a premissa de que sua oferta está centrada nas empresas do setor de hospedagem. Conforme MTUR (2015), a estruturação da base de dados econômica do turismo nacional considera como atividade turística relativa a hospedagem as pessoas jurídicas cadastradas no CEMPRE (Cadastro Central de Empresas) e que compõem as estatísticas da Pesquisa Anual de Serviços (PAS). Os dados estão baseados na Classificação Nacional de Atividades Econômicas (CNAE) e estão englobadas nos códigos 55.10-8 (hotéis e similares) e 55.90-6 (hospedarias, dormitórios, pensões, albergues, campings e outros).

Nesse sentido, o conjunto de fluxos decorrentes dos deslocamentos realizados por proprietários de segundas residências, bem como por pessoas e empresas que arrendam essas moradias, permanece subestimado e obscurecido. À exceção das séries produzidas pelo IBGE, que adotou desde 1991 a coleta da variável territorial no Censo Demográfico, Domicílios de Uso Ocasional (DUO), nenhuma outra base oficial se ocupa dessa informação. Todavia, esta variável estatística está deslocada da base de dados econômica do turismo, compondo exclusivamente informações relativas a domicílios, no âmbito do Censo Demográfico (IBGE, 2010). Vale destacar que o IBGE considera como DUO os domicílios que servem ocasionalmente para uso com a finalidade de descanso de fim de semana, férias e outras finalidades relativas ao tempo livre familiar, não distinguindo se esse uso se restringe aos proprietários e familiares, amigos ou locatários. (IBGEa, 2010).

A relativa invisibilidade do fenômeno da segunda residência também se estende 
para o campo da política pública em turismo, em que pese a incorporação crescente do viés territorial e do desenvolvimento. Com foco na busca da diminuição das desigualdades regionais, ponto central da proposta de governo, o Plano Nacional de Turismo (PNT) 2003-2007 (que sucedeu ao Plano Nacional de Municipalização do Turismo (PNMT)), propôs uma visão de futuro que previa o turismo no Brasil estruturado de forma diversificada, tanto do ponto de vista cultural, como da distribuição espacial. Para atingir tal visão de futuro, o PNT propôs um novo modelo de desenvolvimento baseado em dois pontos estruturantes: parcerias e gestão descentralizada. (Fratucci, 2014).

Inicialmente, no mapeamento feito em 2004, foram identificadas 219 regiões turísticas envolvendo 3.203 municípios. Em 2006, após um trabalho de revisão chegou-se a 200 regiões turísticas, contemplando 3.819 municípios, indicando 396 roteiros turísticos para o mercado nacional (149 regiões e 1.027 municípios). Dentre estes, apenas 87 destinavam-se a ser estruturados para atingirem o padrão de qualidade exigido pelo mercado internacional, o que envolveria um total de 116 regiões turísticas, compostas por 474 municípios. (Brasil, 2007).

O mapeamento realizado pelo Ministério do Turismo brasileiro indica, atualmente, 291 regiões e 2.175 municípios, categorizados conforme o volume de empregos e de estabelecimentos hoteleiros formalizados e os fluxos turísticos nacionais e internacionais (BRASIL, 2017). Um dos aspectos questionáveis refere-se à exclusão de uma parte substancial dos fluxos, aqueles que dizem respeito a essa modalidade específica, que é a segunda residência turística.

É sabido que a mobilização econômica promovida por esses fluxos e pelos atores promotores da dinamização do território é distinta, no que tange às relações sociais e econômicas tradicionalmente compreendidas como turísticas (Muller; Hall \& Keen, 2004; Raffestin, 2009). Nesse caso, as empresas do segmento de construção civil e locações imobiliárias assumem um papel relevante, e, nos destinos em que predomina a segunda residência, esse papel torna-se ainda mais explícito, mesmo que não sejam vistas como empresas turísticas (Coriolano; Barbosa \& Sampaio, 2010). Dimensionar e compreender esses fluxos são pré-condições para avaliar seus efeitos multiplicadores.

Considerando estas reflexões, a pesquisa pautou-se no propósito de explicitar os destinos litorâneos de segunda residência, distribuídos ao longo dos três estados da região sul brasileira. Os dados relativos aos indicadores oficiais de Domicílios de Uso Ocasional foram cruzados com os resultados da pesquisa de mapeamento dos destinos turísticos, que, atualmente, consiste no suporte para o estabelecimento de políticas públicas nesse âmbito.

$\mathrm{O}$ artigo foi estruturado em seis partes, incluindo esta introdução. A política pública de turismo, suas concepções e vieses, é objeto da segunda parte. Em seguida, a terceira parte traz a fundamentação conceitual e teórica acerca da segunda residência turística. Na quarta parte, os procedimentos metodológicos da pesquisa são apresentados, e, na parte subsequente, são analisados os re- 
sultados da pesquisa. Na última parte, são realizados os apontamentos finais e as derivações típicas de pesquisas exploratórias.

\section{AS POLÍTICAS PÚBLICAS EM TURISMO NO BRASIL DESDE OS ANOS 2000}

É recorrente a discussão de que as políticas públicas de turismo são fundamentais para a atuação do poder público, mas também do setor privado, na gestão organizacional da atividade, em âmbitos local (municipal) e regional. Além de a cooperação entre os municípios das regiões de planejamento integrado ser problemática no Brasil, o novo Edital do Ministério do Turismo (2017) para regiões turísticas, que frisa que os recursos são restritos aos que fazem parte do mapa do turismo brasileiro, reforça a discussão. No recorte feito para este artigo, existem destinos que não estão no mapa, mas que têm crescido em representatividade no turismo de segunda residência. Nas políticas do Ministério do Turismo, não há ações e metas para esse segmento, o que é intrigante.

Para entender o processo de mapeamento dos destinos turísticos, é importante uma sucinta revisão sobre a política de regionalização do turismo brasileiro. Apesar de o turismo, ainda que de forma incipiente, ter sido contemplado pela gestão pública desde a década de 1930, destaca-se que, na década de 1990, a Empresa Brasileira de Turismo (Embratur) instituiu o Programa Nacional de Municipalização do Turismo (PNMT), cuja implementação ocorreu nos governos de Fernando Henrique Cardoso (1995 - 2002). A proposta do PNMT era a descentralização, responsabilizando os municípios pela gestão do turismo, por meio de parcerias com a comunidade e com a iniciativa privada. Para facilitar essa articulação, incentivou-se a criação dos Conselhos Municipais de Turismo.

\begin{abstract}
De acordo com Araujo e Taschner (2012), a política nacional de turismo no Brasil assumiu maior visibilidade nos anos 1990, com a transformação da Embratur em Instituto Brasileiro de Turismo. Naquele período, foi instituído o Programa Nacional de Municipalização do Turismo (PNMT), para ampliação da autonomia e participação dos estados e municípios. Foi uma mudança de modelo pela descentralização das políticas. Criação de Conselhos e de Fundos de turismo e planos de desenvolvimento turístico municipal foram suas diretrizes (Araújo e César, 2012). Apesar de importante iniciativa, o PNMT gerou resultados pontuais. O Ministério do Turismo (MTur), como pasta exclusiva, foi criado em 2003, marco na história do turismo brasileiro. A Embratur passou, então, a ser responsável pelo marketing, comercialização e divulgação do Brasil no exterior (Sette \& Tomazzoni, 2017, p. 299).
\end{abstract}

Ainda que fosse coerente delimitar as políticas públicas de gestão da atividade turística às escalas municipais, em função da própria configuração da federação brasileira, em que os municípios são entes constitucionais, a complexidade do turismo implicou que as articulações transcendessem essa delimitação. Os gestores municipais viram-se desafiados a articular as políticas de turismo de suas secretarias com as secretarias dos municípios vizinhos, assumindo visões regionais.

A característica da complexidade do turismo, que ensejou a origem da regionalização, é analisada por diversos autores, entre os quais, Fratucci (2014). Para esse autor, em razão da multiplicidade e da diversidade de 
segmentos, de organizações e de atores produtivos, a atividade turística tem natureza dual, é zonal e reticular. A dimensão espacial reticular é fundamental para a contextualização territorial do turismo, e o conceito referencial mais adequado do que a própria região é "território-rede", que contempla a natureza, tanto zonal (municipal, ou local), quanto reticular (regional) da atividade.

Para Fratucci (2014, p. 43), "esse tem sido, de maneira geral, o equívoco das nossas políticas públicas de turismo. (...) O espaço é compreendido apenas como suporte e matéria-prima, priorizando os interesses de apenas um grupo de agentes do turismo, o dos empresários". O autor argumenta que as políticas não são eficazes na realização de projetos de desenvolvimento da atividade, mas reconhece que o Ministério do Turismo avançou ao contextualizar a política em escala regional.

Após a sua criação, em 2003, o Ministério do Turismo lançou, em 2004, o Programa de Regionalização do Turismo - Roteiros do Brasil (PRT). Para o Ministério (BRASIL, 2007), o Programa é um eixo estruturante do turismo, cujo foco é a geração de empregos e a qualidade de vida, por meio de políticas de desenvolvimento de regiões brasileiras com potencial econômico. A política estratégica governamental do Programa, portanto, é o desenvolvimento regional do turismo.

O documento Diretrizes Políticas consubstancia que a regionalização é o modelo de gestão de política pública descentralizada, coordenada e integrada do turismo, com base na cooperação e na governança (democratização da participação e distribuição de responsabilidades). A configuração regional transcende a delimitação geográfica espacial e define-se pelo planejamento integrado e pelo compartilhamento das ações de promoção e de mercado (marketing e comercialização) turísticos (Brasil, 2004; Feger \& Etges, 2014).

As políticas governamentais e os planos de turismo tornaram-se objetos de estudos por vários pesquisadores e analistas, a exemplo de Beni (2006), que reconhece a coerência das diretrizes e da estruturação institucional para o planejamento do espaço turístico regional. Beni (2006), entretanto, identifica dificuldades de entendimento, de adaptação conjuntural e de implementação das propostas de regionalização do turismo pelas instâncias estaduais e municipais (Brasil, 2007).

A diferença das realidades dos municípios e regiões também desafiou a articulação dos segmentos, ainda que fossem reconhecidas as particularidades econômicas, sociais, culturais e ambientais dos territórios turísticos (Brasil, 2004). Esse contexto implicou reformulações das diretrizes do Programa de Regionalização do Turismo, cuja reedição, em 2007, fundamentou-se no modelo de destinos turísticos indutores, destacando 65 municípios (entre os quais as 27 capitais). A justificativa dos critérios da definição foi o estudo de competitividade, que identificou os principais destinos brasileiros, que, além de seus diferenciais turísticos, liderassem o planejamento e a gestão do turismo em suas regiões.

De acordo com o Ministério do Turismo (MTur, 2007), considerando o Plano de Marketing Internacional - Plano Aquarela e ou- 
tros estudos e pesquisas sobre os investimentos do governo federal, além da análise da potencialidade e infraestrutura dos municípios, foram definidos 65 destinos indutores a partir desses roteiros, que teriam o papel de induzir o desenvolvimento turístico em suas regiões. (...) Sem a pretensão de aprofundar o assunto, é importante ponderar que os critérios para definição dos 65 destinos indutores não foram expostos de maneira clara pelo MTur, tendo sido alvos de questionamentos. Com o intuito de mensurar e monitorar a competitividade desses destinos indutores, o MTur, em parceria com a FGV e o Sebrae Nacional, elaborou a metodologia do Índice de Competitividade Turística (Sette \& Tomazzoni, 2017, p. 300-301).

A análise das experiências e municipalização do turismo, pelo PNMT, e de regionalização do turismo, pelo PRT, mostra que ambos os Programas não tiveram êxito em administrar a complexidade da relação dialética entre municipalização e descentralização. Nesse sentido, o processo de formulação da política nacional de turismo, apesar das dificuldades e dos obstáculos, tem se dinamizado. Os Planos Nacionais de Turismo, 2007 -2010 e 2013-2016 mantiveram as propostas de regionalização com base nos 65 destinos indutores. As diretrizes e os princípios estruturantes do PNT 2007-2010 foram enfatizados pela Lei Geral do Turismo, criada em 2008, e cujos 48 artigos fundamentam a descentralização e a regionalização do turismo (Machado \& Tomazzoni, 2011).

O conceito de regionalização enfrenta uma limitação administrativa, no que diz respeito à estrutura federativa brasileira. Isso porque, em princípio, é possível que as regiões turísticas, definidas com base na característica zonal dos fluxos, possam extrapolar os limites administrativos dos estados brasileiros. Em áreas fronteiriças esta problemática tende a ser mais evidente, como identifica o estudo de Feger (2010). No entanto, em que pese tais limitações, a política de regionalização foi desenhada para ser executada em consonância com o modelo federativo brasileiro, no qual os governos estaduais assumiram papel estratégico na delimitação das regiões e na fomentação dos atores em cada região para o planejamento e promoção dos destinos.

Ainda nesse sentido, os estados brasileiros estabeleceram suas políticas de desenvolvimento do turismo, incorporando as regiões, definindo-as como elementos estratégicos. A observação dos planos estaduais dos estados sul brasileiros, no entanto, indica que não houve definição da construção de bases de dados complementares e que traduzissem as realidades regionais, com algumas exceções de estudos que trazem indicadores sobre a oferta de hospedagem não hoteleira, como se vê no Rio Grande do Sul (ZUANAZZI, 2016). De forma geral, os planos se estruturam a partir de indicadores similares àqueles considerados pelo Ministério do Turismo, que considera os empreendimentos ligados à hospedagem hoteleira como centralizadores da economia turística, além de tomar os atores ligados a este setor como estratégicos no processo de planejamento (RS, 2014; PR, 2016; SC, 2010), sem considerar que, em vários municípios, existam outros atores também relevantes para a dinâmico turística, como é o caso daqueles que se relacionam à segunda residência, construtores, agentes imobiliários e proprietários.

Nesse contexto, o Ministério do Turismo publicou, em 2015, portaria determinando a Categorização dos Municípios das 
Regiões Turísticas do Mapa do Turismo Brasileiro:

\begin{abstract}
Com base em quatro variáveis objetivas - números ocupações formais no setor de hospedagem; número de estabelecimentos formais no setor de hospedagem; estimativa do fluxo turístico doméstico; estimativa do fluxo turístico internacional - e em uma análise de cluster (agrupamento), definiram-se cinco categorias de municípios. Assim, os municípios que possuem médias semelhantes - nas quatro variáveis analisadas - foram reunidos em uma mesma categoria (A, B, C, D ou E). Os resultados obtidos na análise do Mapa do Turismo Brasileiro 2016 indicam: 51 municípios na categoria $A$, que representa os municípios com maior fluxo turístico e maior número de empregos e estabelecimentos no setor de hospedagem; 155 municípios na categoria B; 424 municípios na categoria C; 1219 municípios na categoria D; e 326 municípios na categoria $E$, que representa os municípios que não possuem fluxo turístico expressivo e nem empregos e estabelecimentos formais no setor de hospedagem (Brasil, 2016).
\end{abstract}

O Ministério do Turismo confirma a dinamicidade da política da atividade: "A categorização é um processo dinâmico, assim como o Mapa do Turismo Brasileiro deverá ser atualizada e aperfeiçoada periodicamente" (Brasil, 2016). Observa-se, todavia, a persistência da perspectiva da não percepção dos destinos de segundas residências como elementos dinamizadores da economia turística e da própria implementação prática das diretrizes da política pública. A problematização definida neste artigo permite tomar como hipótese que o fato de que o processo de definição das políticas, bem como do planejamento, tende a ser prejudicado de forma

\footnotetext{
${ }^{3}$ Hall e Muller (2004) falam dessa busca pelos ambientes bucólicos, ambientes imaginados. Nesse sentido, a natureza é uma recriação da natureza com base
}

considerável, ao não definir como linha estratégica a construção de uma base de dados referentes às segundas residências, à mensuração de seus fluxos, bem como à inclusão dos atores vinculados a esse fenômeno, no processo de definição de ações para o desenvolvimento do turismo.

\subsection{A segunda residência turística como um fenômeno atual do turismo}

A segunda residência turística referese a uma tipologia de moradia associada diretamente ao lazer. É consenso que, para se enquadrar nessa condição, o proprietário não deve permanecer nela em período superior a um ano. Trata-se de um fenômeno social que remonta a práticas do Século XVIII, originalmente associadas às práticas da nobreza europeia. Müller, Hall e Keen (2004) destacam que os proprietários de segundas residências são turistas e que os impactos causados pelos fluxos desencadeados por eles são, frequentemente, similares a outras formas de turismo.

Em termos de motivações para aquisição dessas propriedades, o escape da vida da cidade apareceu como clássica justificativa para os habitantes europeus, desde o início do século $X X, e$, continuou sendo um elemento destacado pelos autores na virada para o XXI (Marjavaara, 2008). Adicionalmente, Peterson (1999) sistematiza três categorias de motivos: a) emocionais/psicológicos, nos quais está enquadrada a busca pela natureza ${ }^{3}$, pela paz, por identidade familiar,

em paisagens bucólicas, o imaginário, por sua vez, é oriundo da vida urbana, o que remete às discussões 
ambiente favorável para as crianças, além da necessidade de prestígio; b) lazer e recreação: especialmente em função da busca por espaços privativos de lazer; c) comerciais ou de investimento: relacionados à busca de valorização e renda por meio de locação de imóveis. A busca por um estilo de vida flexível e turístico, que poderia ser agregada aos fatores emocionais listados pelo autor, é indicada por Paris (2006) e Laar (2011) e está vinculada à mobilidade própria do contexto de globalização. Aronsson (2004) acrescenta ainda que a segunda residência expressa um modo de vida no qual os pressupostos de mobilidade e o desejo de habitar estão intimamente relacionados.

Compreender os impactos gerados pelas segundas residências é outra questão chave para os pesquisadores. 0 primeiro e mais comumente mencionado é o fator econômico de geração de empregos e seus efeitos multiplicadores de renda, que vêm sendo discutidos desde os anos 1970. Marjavaara (2008) destaca que elas estimulam a manutenção de empregos, inclusive, daqueles que estão em extinção, além de possibilitar a sobrevivência de pequenos estabelecimentos comerciais. $\mathrm{O}$ autor reitera o que outros pesquisadores indicam, especificando que, em contrapartida, o aquecimento da demanda por segundas residências provoca o inflacionamento do preço da terra e do custo de vida, por conseguinte, em vários lugares se observa a inviabilização do acesso às gera- ções subsequentes de moradores permanentes, o que é particularmente visível em áreas campestres (Brida, Osti \& Santifaller, 2011).

O turismo de segunda residência compartilha com as outras formas de turismo a necessidade de infraestrutura e de superestrutura turísticas, a carência de serviços complementares, a existência de fatores motivacionais para viagens, a existência de um processo de organização das viagens, a geração de impactos socioeconômicos e espaço-ambientais, a geração de gastos e o fator multiplicador, além do desenvolvimento de paradigmas e padrões (Muller, Hall \& Keen, 2004).

Existem, todavia, especificidades do turismo de segunda residência. Em primeiro lugar, é uma modalidade de turismo vinculada a uma forma de hospedagem, que, por sua vez, está conectada ao setor de construção civil e ao mercado imobiliário. Em vários momentos, a principal motivação para aquisição é a aspiração por retornos financeiros de investimento, incluindo aqueles derivados da locação de imóveis. A organização das viagens é realizada de forma privada e, por definição, há um caráter repetitivo. Também existe a possibilidade de que os impactos das segundas residências sejam mais permanentes. Por fim, os gastos dos turistas envolvem não apenas aqueles relativos à permanência no local, mas também à manutenção das residências (Karayiannis, lakoviou \& Tsartas, 2013; Vágner \& Fiolová, 2011). 
No Brasil, os primórdios do turismo de segunda residência, bem como a valorização das áreas litorâneas, remontam à mudança da corte portuguesa para a colônia, em 1808, que promoveu a migração dos hábitos relacionados ao termalismo, bem como às influências dos médicos que prescreviam os tratamentos por meio do uso das águas. No início do século $\mathrm{XX}$, o desejo pela praia tornou-se menos incipiente e sofreu os impactos da combinação entre usos medicinais, políticas higienistas e códigos morais que remodelaram algumas cidades litorâneas brasileiras. As cidades balneárias, em geral planejadas por companhias privadas, a exemplo da cidade do Guarujá (litoral do estado de São Paulo), refletiam uma composição que continha a construção de grande hotel e casas de veraneio. Foi, entretanto, desde o Rio de Janeiro que irradiou a influência sobre formas de uso e apropriação da praia, ressoando as práticas europeias (SCHOSSLER, 2010). No que se refere à região sul, particularmente no Rio Grande do Sul, os imigrantes alemães tornaram-se os principais difusores da prática da formação de vilas turísticas nas proximidades do mar, além de terem sido precursores na conversão dos espaços terapêuticos em áreas de recreação (Pereira, 2014).

A literatura científica dedicada à historiografia da ocupação balneária das cidades litorâneas brasileiras aponta movimentos distintos no processo de ocupação. A influência europeia foi evidenciada no Rio de Janeiro ao longo do século XIX, reflexo do cotidiano da família real e que se apresentou como ideal a ser seguido por uma elite ascendente. Da segunda metade do século XIX em diante, o processo de imigração trouxe a influência britânica e mais ainda a germânica, particularmente na região sul (Pereira, 2014). Os registros são mais claros sobre isto no Rio Grande do Sul e de forma menos enfática, mas também relevante, sobre Santa Catarina e Paraná.

No Rio Grande do Sul, a etapa inicial da utilização dos espaços litorâneos se relaciona às práticas curistas e se desenvolveu mais fortemente nos locais em que os meios de transporte viabilizaram os fluxos, como na atual praia do Cassino, em Rio Grande. Em Santa Catarina, a capital Florianópolis foi transformada em espaço privilegiado das elites teuto-brasileiras (Schossler, 2010). No Paraná, também se percebe a influência alemã, em que pese o menor volume da imigração para Curitiba, cuja relativa proximidade do litoral viabilizou sua apropriação para práticas relacionadas à saúde e ao lazer (Gobbi, 2001; Bigarella, 2009).

No cenário atual acerca da segunda residência, cruzando referências nacionais e internacionais, foram identificadas duas grandes vertentes. A primeira delas expressa uma perspectiva mais tradicional, representada pela edificação de moradias que possibilitam usufruir turisticamente do espaço, seja no campo ou na cidade, em áreas de montanha ou litorâneas. Os espaços tornamse desejados para essa finalidade, em decorrência de seus atributos turísticos, que podem ser naturais ou artificiais. A demanda por eles também cresce, fortemente associada à ampliação da mobilidade humana contemporânea (Paris, 2006; Aronson, 2004; Duval, 2004; Laar, 2011). Essa modalidade, em 
que pese a classificação de tradicional, continua presente e em expansão, tanto no Brasil, como em outros países, incluindo aqueles que possuem longa tradição nessa área.

A segunda vertente está associada às novas e potencializadas formas de mobilidade humana, que beneficiam parcelas da população mundial que passaram a demandar um novo estilo de vida, intitulado por alguns autores como turístico (Duval, 2004; Assis, 2012). Um dos aspectos mais fortes na sua distinção é a vinculação com a lógica financeirizada do capitalismo, que altera as formas de produção e de oferta das unidades de hospedagem, além de promover uma mescla entre a hospedagem hoteleira e não hoteleira. O perfil da segunda residência contemporânea tem dirigido a expansão de investimentos nesse segmento turístico, e, sua proeminência se apresenta em diversos contextos espaciais, na Costa Sul da Espanha, na América Central e mesmo no Brasil, com mais ênfase na região nordeste, mas também identificada em alguns pontos do litoral sul brasileiro, particularmente, em Santa Catarina (Barrantes-Reynolds, 2011; Mazón \& Aledo, 2005; Silva \& Ferreira, 2012; Coriolano \& Sampaio, 2012).

Tanto Coppock (1977), que organizou a primeira coletânea conhecida sobre o tema das segundas residências, como Hall e Muller (2004) que recolocaram a mesma pergunta chave sobre os efeitos das segundas residências turísticas para o lugar, "curse or blessing?", reiteraram que esse fenômeno tem se mantido relevante, à medida que se atualiza, persistindo crucial na definição das identidades territoriais. Mas, para além disso, suas novas feições representam uma das facetas das transformações do próprio turismo. Trata-se de um reflexo das mudanças que afetam cada um dos elementos fundantes do sistema turístico moderno, em conversão para o contemporâneo.

\section{PROCEDIMENTOS METODOLÓGICOS}

Do ponto de vista metodológico, a abordagem do tema nesse recorte foi quantitativa e de caráter exploratório. A perspectiva exploratória guiou a revisão bibliográfica, com vistas a compreender a política pública de desenvolvimento turístico e suas prioridades, bem como discutir o fenômeno da segunda residência turística e a forma pela qual tem sido abordado. Identificar o caráter atual e a preocupação dos gestores do turismo em mensurar e propor ações relacionadas aos fluxos da residência secundária constituem elementos importantes para subsidiar a reflexão acerca da sua omissão nas políticas públicas brasileiras.

Os dados referentes à residência caracterizada como de uso ocasional, apurados nos Censos Demográficos do IBGE (2000 e 2010), foram assumidos como a estatística básica de residências secundárias no Brasil. Esses foram coletados do sistema SIDRA (Sistema IBGE de Recuperação Automática de Dados), com base na Tabela 1310. Tal base, conforme exposto anteriormente, é considerada como indicador para aferição do uso residencial de lazer e descanso. Independentemente da motivação do proprietário ao adquirir o imóvel, e, ainda que o uso seja para locação destinada ao lazer, a classificação continua sendo adequada para referenciar o volume de residências secundárias. 
Adicionalmente, foram analisados os dados produzidos no processo de mapeamento do turismo brasileiro, que gerou a classificação atual dos destinos. Conforme MTUR (2015a), o processo está sustentado na aferição de quatro variáveis combinadas. São elas: 1) número de estabelecimentos formais, cuja principal atividade é hospedagem, obtidos da Relação Anual de Informações Sociais (RAIS, Ministério do Trabalho e Emprego); 2) número de empregos formais no setor de hospedagem (RAIS, Ministério do Trabalho e Emprego); 3) estimativa de turistas a partir do Estudo de Demanda Turística Doméstica, produzido pela Fundação Instituto de Pesquisas Econômicas (FIPE/Ministério do Turismo); 4) estimativa de turistas a partir do Estudo de Demanda Internacional. Com essas variáveis foram definidos estratos de classificação. Cada classe na qual foram enquadrados os destinos brasileiros foi definida por valores médios de volumes em cada uma das variáveis especificadas, que foram utilizados como referência no processo de cruzamento e análise.

Realizou-se um estudo quantitativo de caráter exploratório, tomando a estatística descritiva como recurso para análise dos resultados, com o intuito da estruturação e interpretação dos cruzamentos de dados (Severino, 2013). A análise dos dados secundários envolveu coleta, sistematização e interpretação, tendo em vista explicitar a participação, em termos volumétricos, das segundas residências litorâneas. Os dados foram coletados, exclusivamente, para os municípios litorâneos, dos três estados da região sul brasileira. Em seguida, foram analisados em processo comparativo aos resultados do pro- cesso de ranqueamento dos destinos turísticos realizado pelo Ministério do Turismo, nesse caso evidenciados, exclusivamente, os destinos litorâneos pertencentes aos três estados.

\section{ANÁLISE DOS RESULTADOS DA PESQUISA}

No Brasil do início do século XX, o desejo pela praia tornou-se menos incipiente e sofreu os impactos da combinação entre usos medicinais, políticas higienistas e códigos morais que remodelaram algumas cidades litorâneas brasileiras. As cidades balneárias, em geral planejadas por companhias privadas, a exemplo do Guarujá (litoral do estado de São Paulo), refletiam uma composição que continha a construção de grande hotel e casas de veraneio. Foi, no entanto, desde o Rio de Janeiro que a influência europeia irradiou sobre formas de uso e apropriação da praia (Schossler, 2010). No que se refere à região sul, particularmente no Rio Grande do Sul, os imigrantes alemães foram os principais difusores da prática de organização de espaços turísticos vinculados às áreas costeiras, constituindo os primeiros grupos de residentes secundários, além de investidores em meios de hospedagem hoteleira (Pereira, 2014).

Em que pese o fenômeno da segunda residência não estar vinculado estritamente ao contexto do pós-guerra, o crescimento da infraestrutura rodoviária foi fundamental para sua expansão, em função da maior acessibilidade aos núcleos turísticos, incluindo as vilas costeiras. Do ponto de vista das estatísticas nacionais, desde os anos 1970, tornouse visível o volume de segundas residências 
por meio da apuração dos Censos Demográficos (Assis, 2003; Sena \& Queiroz, 2006). Os dados apurados pelo IBGE, permitem explicitar sua magnitude e distribuição espacial. Em termos de volume, a região Sul brasileira é aquela em que a participação percentual das residências secundárias no universo total é mais expressiva, tanto na apuração do Censo de 2000, como no de 2010. No último Censo, $7 \%$ do total de residências nessa região possuíam o referido perfil.

Nos três estados, observa-se que a presença das residências secundárias, estimadas com base na apuração oficial do IBGE, é substancial. $O$ volume de residências secundárias em relação ao total é expressivo, particularmente, nas áreas costeiras dos estados do Paraná (38\%) e Rio Grande do Sul (41\%). Isso comprova que a valorização do ócio e do lazer, associados ao hábito de veranear próximo ao mar, constituindo estâncias balneares, observada desde o século XIX no litoral dos três estados, permanece como um traço relevante do processo de ocupação desses espaços (Schossler, 2010; Enke, 2013; Sayão, 2012; Gobbi, 1997; Esteves, 2011).

Além disso, entre 2000 e 2010, os três estados apresentaram crescimento do volume total de residências secundárias: o estado do Paraná apresentou a menor taxa de crescimento, $14 \%$; Santa Catarina, $28 \%$, e Rio Grande do Sul, com 24\%. Ainda assim, em volume total, como no crescimento, o fenômeno da residência turística permanece não apenas expressivo nessa região, como ainda atuam fatores motivadores de crescimento. Essa longevidade constitui um importante indicador de que o desenvolvimento turístico está associado a esse segmento nesse contexto.

\subsection{Os principais destinos de segunda resi- dência nos três estados do Sul em seu posicionamento na categorização turís- tica divulgada pelo Ministério do Tu- rismo}

O mapa do turismo brasileiro especifica uma classificação dos destinos, que vai de $A$ a $E$, baseada em quatro variáveis, que traduzem o volume de empregos e de estabelecimentos hoteleiros formalizados, bem como os fluxos de turistas nacionais e internacionais. Os destinos categorizados como $\mathrm{A}$ concentram a maior parte dos empregos, estabelecimentos e fluxos turísticos, tanto nacionais, como internacionais. Em contrapartida, aqueles que foram designados como classe $E$ não tiveram pontuação em quaisquer dessas variáveis (Tabela 1).

Os destinos enquadrados nas classes A e B são aqueles em que o turismo está mais desenvolvido, particularmente, no que tange à dimensão econômica. Por conseguinte, a atividade turística exerce forte impacto multiplicador nesses locais. O multiplicador econômico possui uma especificidade importante no caso da atividade turística. Visualizase que a atividade turística desencadeia no destino um conjunto de investimentos, tanto para atender os turistas, como outras demandas correlatas. Lage e Milone (1991) indicam três dimensões desse processo, que se traduzem no multiplicador da produção, da renda e dos empregos. 
Tabela 1 - Classificação de Destinos Turísticos Brasileiros

\begin{tabular}{ccccc}
\hline Categorização & \multicolumn{4}{c}{ VALORES MÉDIOS POR CATEGORIA } \\
& Variável 1 & Variável 2 & Variável 3 & Variável 4 \\
\hline A & 2.401 & 190 & 140.474 & 1.775 .071 \\
B & 458 & 36 & 7.535 & 235.855 \\
C & 98 & 11 & 587 & 58.851 \\
D & 11 & 2 & 0 & 0 \\
E & 0 & 0 & 0 & 0 \\
\hline
\end{tabular}

Variável 1: Empregos Formais em empresas de hospedagem; Variável 2: Número de estabelecimentos formais de hospedagem; Variável 3: Estimativa de Fluxo de Turistas Internacionais; Variável 4: Estimativa de fluxo de turistas domésticos. Fonte: BRASIL. Ministério do Turismo (Mapa do Turismo Brasileiro. http://www.mapa.turismo.gov.br/).

Organização dos autores

Na região Sul, foram identificados 13 destinos classificados como $A$ e $B$, sendo quatro na primeira classe e nove na segunda. Entre os destinos classe A, em Santa Catarina, estão Balneário Camboriú, Bombinhas e Florianópolis; no Rio Grande do Sul, o município de Torres é o único nessa classificação. O processo de classificação é um contributo para reflexão sobre a centralidade dos fluxos turísticos nas regiões, todavia, não está claro de que forma a política pública irá tornar essa informação operacional para o estímulo do desenvolvimento regional, tendo em vista seu caráter zonal e complexo, como já foi alertado por Fratucci (2014).

Conforme é evidenciado na Tabela 2, entre esses destinos, 12 têm elevada expressividade das segundas residências turísticas, que representam parte da hospedagem extra hoteleira. A única exceção é o município de Itajaí (SC), cujo perfil portuário oprime a expansão das segundas residências, mesmo assim, observou-se expressivo crescimento do volume dessa modalidade residencial na última década. Inclusive, nota-se que os destinos de classe A apresentam mais de $20 \%$ de residências secundárias, e, à exceção de Balneário Camboriú, apresentaram crescimento significativo na última década.

Esse primeiro dado possibilita confirmar, nos destinos que concentram a maior parte da dinâmica do turismo no litoral de cada estado, que o potencial multiplicador da economia das segundas residências turísticas, também em termos de geração de empregos (diretos e indiretos) e de estimulação de fluxos, foi desconsiderado. Nesse sentido, os dados da estatística oficial do IBGE, correlacionados à categorização, revelam que há um subdimensionamento do potencial econômico desses destinos turísticos.

Conforme se observa nos documentos relativos à política pública nacional de turismo (Brasil, 2007), bem como os estaduais (RS, 2014; SC, 2010; PR, 2016), o objetivo central é o fomento ao processo de geração de emprego e renda, associados à qualidade de vida. Nesse sentido, ao identificar que os destinos com maior representação turística dos estados também possuem volume significativo de residências secundárias e, quase invariavelmente, têm apresentado cresci- 
mento desse tipo de domicílio, pode-se indicar que a subjugação dessa variável constitua mais um dificultador do processo de imple- mentação das políticas com sucesso, agregando aos elementos já apontados por Beni (2006).

Tabela 2 - Destinos Turísticos do litoral Sul brasileiro classificados como A e B, conforme os critérios do Ministério do Turismo

\begin{tabular}{|c|c|c|c|}
\hline Destinos por Estado & Categoria & $\begin{array}{c}\text { VOLUME DE } \\
\text { RESID. SECUND. } \\
2010(\%)\end{array}$ & $\begin{array}{c}\text { CRESCIM. } \\
2010 / 2000(\%)\end{array}$ \\
\hline Guaratuba-PR & $B$ & $51 \%$ & $17 \%$ \\
\hline Matinhos - PR & B & $65 \%$ & $20 \%$ \\
\hline $\begin{array}{l}\text { Balneário Camboriú - } \\
\text { SC }\end{array}$ & $A$ & $30 \%$ & $1 \%$ \\
\hline Bombinhas - SC & $A$ & $39 \%$ & $43 \%$ \\
\hline Florianópolis - SC & $A$ & $28 \%$ & $24 \%$ \\
\hline Garopaba - SC & B & $28 \%$ & $33 \%$ \\
\hline Itajaí - SC & B & $2 \%$ & $64 \%$ \\
\hline Itapema - SC & B & $42 \%$ & $22 \%$ \\
\hline Penha - SC & B & $38 \%$ & $14 \%$ \\
\hline São Fco do Sul - SC & B & $39 \%$ & $43 \%$ \\
\hline Capão da Canoa - RS & B & $59 \%$ & $32 \%$ \\
\hline Torres - RS & $A$ & $34 \%$ & $18 \%$ \\
\hline Tramandaí - RS & B & $53 \%$ & $20 \%$ \\
\hline
\end{tabular}

Outro aspecto identificado no processo de análise dos dados é que os destinos classificados com $C$ e $D$ possuem um número reduzido de empreendimentos hoteleiros formais, revelando baixa expressividade da hospedagem hoteleira na movimentação de suas economias. No entanto, quando o foco se torna as residências secundárias, a percepção é alterada, tanto pelo volume expressivo de unidades, como pela recente expansão. Trata-se de indicador de que esses municípios estejam sendo dinamizados economicamente por essa modalidade turística.
De acordo com Müller, Hall e Keen (2004), deve-se destacar que os residentes secundários são turistas, e os fluxos mobilizados por eles causam impactos similares aos demais segmentos. Adicionalmente, as segundas residências possibilitam manter empregos em extinção em vários lugares, ampliando o leque da sua geração, o que é algo relevante, dada a tendência crescente de extinção de postos de trabalho na economia contemporânea (Marjavaara, 2008).

Nessa perspectiva, ao selecionar os municípios litorâneos dos três estados que 
apresentaram volume mínimo de 10 mil residências secundárias, em 2010, novamente, foram encontrados 13 destinos. Entre eles, cinco estão classificados como C e D: Pontal do Paraná/PR; Jaguaruna/SC; Imbé, Cidreira e Xangri-lá/RS. Nesses, as residências secun- dárias representam mais de $50 \%$ do total, além disso, alguns casos, como Cidreira e Xangri-lá/RS, bem como Jaguaruna/SC apresentaram taxas superiores a $20 \%$ de crescimento do total dessas residências (Ver Tabela 3).

Tabela 3 - Destinos Turísticos do litoral Sul brasileiro com maior volume de residências secundárias e sua categorização turística pelos critérios do MTUR

\begin{tabular}{lccc}
\hline $\begin{array}{c}\text { Destinos com maior vo- } \\
\text { lume de DUO por Es- } \\
\text { tado da Região Sul }\end{array}$ & $\begin{array}{c}\text { VOLUME DE } \\
\text { RESID. SE- } \\
\text { CUND. 2010 }\end{array}$ & $\begin{array}{c}\text { CRESCIMENTO } \\
\mathbf{2 0 1 0 / 2 0 0 0 ~ ( \% ) ~}\end{array}$ & CATEGORIZAÇÃO \\
\hline Matinhos - PR & 21.411 & $20 \%$ & $\mathrm{~B}$ \\
Guaratuba - PR & 12.178 & $17 \%$ & $\mathrm{~B}$ \\
Pontal do Paraná - PR & 17.695 & $9 \%$ & $\mathrm{C}$ \\
\hline São Francisco do Sul - SC & 10.334 & $43 \%$ & $\mathrm{~B}$ \\
Jaguaruna - SC & 10.587 & $42 \%$ & $\mathrm{D}$ \\
Florianópolis - SC & 25.139 & $24 \%$ & $\mathrm{~A}$ \\
Itapema - SC & 13.547 & $22 \%$ & $\mathrm{~B}$ \\
Balneário Camboriú - SC & 19.812 & $1 \%$ & $\mathrm{~A}$ \\
Capão da Canoa - RS & 23.990 & $32 \%$ & $\mathrm{~B}$ \\
Xangri-lá - RS & 11.571 & $28 \%$ & $\mathrm{C}$ \\
Tramandaí - RS & 19.134 & $20 \%$ & $\mathrm{~B}$ \\
Imbé - RS & 18.438 & $18 \%$ & $\mathrm{C}$ \\
Cidreira - RS & 12.792 & $9 \%$ & $\mathrm{C}$ \\
\hline
\end{tabular}

Fonte: IBGE (2000; 2010); BRASIL.Ministério do Turismo (Mapa do Turismo Brasileiro. http://www.mapa.turismo.gov.br/). Organização dos autores

Uma característica diferencial dos destinos de segundas residência é que o setor de construção civil e o mercado imobiliário compõem a dinâmica turística de modo bastante distinto em relação aos demais. Para mensurar os fluxos turísticos, bem como para apreender o volume de empregos gerados, é importante acompanhar os movimentos desses dois segmentos. Além disso, o proprietário de uma residência secundária estabelece uma relação duradoura com o destino. Assim, os gastos do turista extrapolam o período de sua permanência, em função da necessidade de manutenção de sua propriedade, além da geração dos tributos relativos à propriedade da terra. Isso posto, em que pese a forma diferente de estimular a economia, a contabilização de todas estas variáveis poderia reposicionar esses municípios no Mapa Turístico Brasileiro, incluindo parte deles que estão fora do ranking.

Outro aspecto que chama atenção nesses dados diz respeito ao crescimento praticamente inexpressivo das segundas resi- 
dências no destino Balneário Camboriú, em Santa Catarina, para o qual essa modalidade turística constitui parte de seu processo de ocupação. Soares (2012) revela que existe uma oferta significativa nesse destino, mas que o ritmo de seu crescimento arrefeceu, em decorrência da desaceleração da economia brasileira. Além disso, percebe-se que os empreendimentos turísticos imobiliários desse destino atraem o turista secundário tradicional, mas também o público de terceira idade com renda mais elevada, que se comporta com um residente permanente, com perfil de turista. Viver em ritmo de férias e usufruir de forma privilegiada da paisagem constituem elementos importantes do mercado imobiliário do município. Os movimentos de expansão nesse destino reiteram uma dinâmica contemporânea, que entrelaça as segundas residências ao capital imobiliário e ao setor financeiro que direciona recursos para esse perfil de empreendimentos híbridos de hospedagem hoteleira e residência (Barrantes-Reynolds, 2011; Mazón-Aledo, 2005; Coriolano \& Sampaio, 2012).

O último aspecto destacado nesta análise diz respeito aos destinos que apresentaram maior expansão no volume de residências secundárias na última década. Como se vê na Tabela 4, à exceção dos destinos paranaenses, os demais são incipientes, mas com incremento muito expressivo na última década. Todos esses foram classificados como D no mapa do turismo, e um deles (Pinhal/RS) nem mesmo está classificado. Percebem-se indícios de que os destinos catari- nenses e riograndenses estejam passando por um processo de reconfiguração espacial, por meio dos investimentos em residências secundárias. Certamente, esse aspecto vem promovendo a redefinição das bases da economia, eventualmente, transferindo ocupações tradicionais para as atividades vinculadas à construção e à manutenção de residências de turistas. Processo que contribui para ratificar a atualidade do fenômeno, tal como destacado por Müller, Hall e Keen (2004), além de estimular substancial incremento nas finanças públicas municipais, tornando as municipalidades mais interessadas nessa modalidade de turismo que no fomento de outros segmentos.

Nesse sentido, os dados interpretados reiteram que as segundas residências constituem uma modalidade relevante de hospedagem no litoral do sul do Brasil. Uma parte dos destinos turísticos têm sua dinâmica turística definida por ela, o que também gera empregos, renda, bem como fluxos de turistas nacionais e internacionais. Há ainda aqueles destinos em que existe uma combinação entre as modalidades de hospedagem, nos quais os estabelecimentos de hospedagem apresentam-se como relevantes, em termos de volume e de expansão, na movimentação das economias locais e regionais. A classificação do mapeamento turístico, no entanto, não captura esses dois movimentos, estando restrita ao que se refere à hospedagem hoteleira convencional (hotéis, pousadas e afins). 
Tabela 4 - Destinos Turísticos do litoral Sul brasileiro que apresentaram maior expansão do número de residências secundárias e sua categorização turística pelos critérios do MTUR

\begin{tabular}{|c|c|c|c|}
\hline $\begin{array}{c}\text { Destinos com maior } \\
\text { crescimento de DUO } \\
\text { por Estado da Região } \\
\text { Sul }\end{array}$ & $\begin{array}{l}\text { VOLUME DE } \\
\text { RESID. SE- } \\
\text { CUND. } 2010\end{array}$ & $\begin{array}{l}\text { CRESCIMENTO } \\
2010 / 2000(\%)\end{array}$ & $\begin{array}{l}\text { CATEGO- } \\
\text { RIZAÇÃO }\end{array}$ \\
\hline Matinhos - PR & 21.411 & $20 \%$ & B \\
\hline Guaratuba - PR & 12.178 & $17 \%$ & B \\
\hline $\begin{array}{l}\text { Governador Celso Ra- } \\
\text { mos-SC }\end{array}$ & 2.903 & $108 \%$ & C \\
\hline Biguaçu - SC & 1.108 & $96 \%$ & $\mathrm{D}$ \\
\hline Araquari - SC & 939 & $76 \%$ & D \\
\hline Pinhal - RS & 17 & $467 \%$ & $*$ \\
\hline São José do Norte - RS & 1.948 & $90 \%$ & $\mathrm{D}$ \\
\hline Mostardas - RS & 3.210 & $50 \%$ & $\mathrm{D}$ \\
\hline
\end{tabular}

\section{APONTAMENTOS FINAIS}

O panorama analítico apresentado na seção 3 possibilita vislumbrar que a segunda residência turística constitui um elemento substancial do turismo no litoral sul brasileiro, o que é condizente com o peso histórico dessa modalidade de hospedagem. Decorrentes dela advêm uma série de fluxos, desencadeados a partir da ação do turista, proprietário, locatário. À guisa de exemplo, pode ser citada a arrecadação de tributos, incluindo aí o imposto sobre a propriedade, que é destacável em destinos com forte presença dessas residências. Os serviços associados à limpeza, manutenção e reparo de residências também constituem vetores importantes de gastos dos turistas de segunda residência no destino e não estão circunscritos ao período de uso. Além disso, a oferta de unidades habitacionais não hoteleiras, por meio de locação de imóveis, também gera fluxos, agregando os hóspedes não proprietários.

As ressonâncias, todavia, não se restringem ao campo econômico, estendem-se a todos os aspectos da dinâmica territorial, com impactos sociais, culturais, políticos e ambientais. Novos atores assumem relevância nas decisões sobre os rumos do turismo, entre os quais podem ser nominados os empreiteiros e gestores imobiliários. Nos destinos globalizados, com maior afluxo de capitais, espera-se a valorização exacerbada do preço da terra, que por sua vez, pode inviabilizar o acesso da população perenizada.

Considerando a área explicitada no artigo, composta por toda zona costeira da região Sul brasileira, envolvendo três estados, há que se saber que existem diversas dinâmicas. Em cada um dos estados, podem 
ser identificados os destinos nos quais o turismo de segunda residência teve início nas primeiras décadas do século $X X$, bem como aqueles em que essa modalidade apenas recentemente tem alterado as características tradicionais do lugar. Além disso, existem destinos nos quais o setor hoteleiro e extra hoteleiro (associado à segunda residência) articulam-se e complementam-se, bem como aqueles em que a segunda residência constitui o único motor da atividade turística.

Nesse sentido, explicita-se que a desconsideração desses fluxos e dessas dinâmicas territoriais no âmbito da política pública de turismo tende a gerar fortes distorções no planejamento, na sua implementação e nos resultados que poderão ser obtidos. Sua apreensão, no entanto, requer um esforço de levantamento, sistematização e análise estatística distinto daquele que deve ser empreendido para mensurar os fluxos econômicos advindos dos estabelecimentos empresariais relacionados a hospedagem.

Além disso, considera-se que é muito relevante reconsiderar o trade turismo nesses destinos, e, quanto mais relevante o peso das segundas residências na determinação da dinâmica econômica do turismo da região, mais premente se torna a mudança de percepção dos atores determinantes para o seu desenvolvimento. Parte do setor de construção civil, mas mais especificamente o segmento imobiliário, assumem funções importantes e até mesmo determinantes na definição dos destinos turísticos.

Entende-se, pois, a necessidade de reconhecer os avanços institucionais e de definição de políticas, em particular, da proposta de regionalização que assume a característica zonal do turismo como premissa. Todavia, o investimento em um sistema nacional de captação de informações mais refinado, à guisa de tantos outros países que compreendem a relevância do turismo como atividade econômica e de seus profundos impactos socioespaciais, torna-se crucial para trazer mais assertividade às políticas de desenvolvimento turístico.

\section{REFERÊNCIAS}

Aronson, L. (2004). Place attachment of vacation residences: between tourists and permanent residents. Tourism, mobility and second homes - between elite landscap and common ground. Edited by Michael Hall and Dieter K. Muller, Frankfurt Lodge, 75-86.

Assis, L.F. (2003). Turismo de segunda residência: a expressão espacial do fenômeno e as possibilidades de análise geográfica. Revista Território, Rio de Janeiro, 7 (11/13), p. 107-122.

ASSIS, L.F. (2012). Entre o turismo e o imobiliário: veIhos e novos usos das segundas residências sob o enfoque da multiterritorialidade - Camocim/CE. (Tese). Doutorado em Geografia. Programa de Pós-Graduação em Geografia Humana da Universidade de São Paulo, São Paulo.

BARRANTES-REYNOLDS, M.P. (2011). The expansion of "real estate tourism" in coastal areas: its behaviour and implications. RASAALA: Recreation and Society in Africa, Asia and Latin America, 2(11), s/p. Disponível em: $\quad$ http://davinci.lib.uoguelph.ca/index.php/rasaala/article/view/1549/2141 Acessado em Março de 2016.

Beni, M.C. (2006). Política e planejamento do turismo no Brasil. São Paulo, Aleph.

Bigarella, J.J. (2009). Matinho: homem e reminiscências. Curitiba, Editora Fundo de Cultura.

Brasil. Ministério do Turismo. (2004). Programa de regionalização do turismo: roteiros do brasil: diretrizes operacionais. Brasília, Ministério do Turismo. 
(2007). Plano nacional de turismo 2007-2010 Uma Viagem de Inclusão. Brasília, Ministério do Turismo.

. (2016). Mapa do turismo. Brasília, Ministério do Turismo. Disponível em: http://mapa.turismo.gov.br/mapa/init.html\#/home Acessado em Novembro de 2016.

Brida, J.G.; Osti, L.; Santifaller, E. (2011). Second homes and the need for policy planning. Tourismos: an international multidisciplinary journal of tourism, 6(1), 141-165.

Coriolano, L.N.M.T.; Barbosa, L.M.; Sampaio, C.F. (2010). Veraneio, turismo e especulação imobiliária no Porto das Dunas - litoral cearense. II Congreso Latinoamericano de Investigación turística, reflexiones e contribuciones - Tempo Libre. Turismo y Recreacion. Mar del Plata, 14(1).

Coriolano, L.N.; Sampaio, C.F. (2012). Veraneio, turismo e especulação imobiliária no Porto das Dunas litoral cearense. Coriolano, L.N.; Vasconcelos, F.P. Turismo, território e conflitos imobiliários. Fortaleza: EDUECE, 2012, 201-218.

Duval, D.T. (2004). Mobile migrants: travel do second homes. Tourism, mobility and second homes - between elite landscap and common ground. Edited by Michael Hall and Dieter K. Muller, Frankfurt Lodge, 8796.

Enke, R.G. (2013). O espetáculo do mar em uma estação balneária no Rio Grande do Sul - a vilegiatura marítima na Villa Sequeira / Praia do Cassino (18851960). Tese (Doutorado em História). Programa de Pós-Graduação em História Social da Faculdade de Filosofia, Letras e Ciências Humanas da Universidade de São Paulo, São Paulo.

ESTEVES, C. J.O. (2011). Vulnerabilidade socioambiental na área de ocupação contínua do litoral do Paraná$B R$. Tese (Doutorado em Geografia), Universidade Federal do Paraná, Curitiba.

Feger, J. E. (2010). Regionalização do turismo na área de influência dos municípios de Marcelino Ramos (RS) e Piratuba (SC). Tese (Doutorado em Desenvolvimento Regional), Universidade Santa Cruz do Sul (UNISC), Santa Cruz do Sul.
Feger, J. E.; Etges, V. E. (2014). Regionalização para o planejamento do desenvolvimento turístico: uma discussão sobre critérios para a determinação de áreas com vistas a aplicar a política pública para o setor. Pimentel, T. D.; Emmendoerfer, M. L.; Tomazzoni, E. L. (Org.). Gestão Pública do Turismo no Brasil: teorias, metodologias e aplicações. Caxias do Sul/RS: EDUCS, 231-255.

Fratucci, A. (2014). Turismo e território: relações e complexidade. Caderno Virtual de Turismo - Hospitalidade e políticas públicas em turismo. 14(1), 87-96.

Gobbi, E. (1997). Gerenciamento costeiro: análise de casos do litoral do Paraná sob a perspectiva da Engenharia Costeira. Tese (Doutorado em Engenharia), Universidade Federal do Rio de Janeiro.

Hall, C.M.; Muller, D.K. (2004). Introduction: second homes, curse or blessing? Revisited. Tourism, mobility and second homes - between elite landscape and common ground. Edited by Michael Hall and Dieter K. Muller, Frankfurt Lodge, 3-15.

IBGE. Instituto Brasileiro de Geografia e Estatística. (2000; 2010). Censo Demográfico. Brasília, IBGE. Disponível em: http://www.ibge.gov.br/home/ Acessado em: Julho de 2016.

IBGEa. Instituto Brasileiro de Geografia e Estatística. Guia do censo: glossário. Brasília, IBGE. Disponível em: http://censo2010.ibge.gov.br/materiais/guia-docenso/glossario.html Acessado em: Outubro de 2016.

Karayiannis, O.; lakodivou, O.; Tsartas, P. (2013). Historic, symbolic aspects and policy issues of second home phenomenon in the Greek tourism context: the Cyclades case study. Roca, Z. (Ed.). Second home tourism in Europe: lifestyle issues and policy responses. Ashgate Publishing, Farnham, 331 p.

Laar, S.V. (2011). Economic implications of second home development in South Africa. Master's Thesis, University of Utrech.

Lefebvre, H. (2008). A Revolução Urbana. Belo Horizonte, Editora UFMG.

(2001). O direito à cidade. São Paulo: Centauro.

Machado, A.L.; Tomazzoni, E.L. (2011). A regionalização turística do Rio Grande do Sul e sua contribuição como referência para a gestão regionalizada do tu- 
rismo no Brasil. Revista Brasileira de Pesquisa em Turismo. 5(2), 226-247. Disponível em: https://www.rbtur.org.br/rbtur/article/view/386/460 Acessado em Março de 2016.

Marjavaara, R. (2008). Second home tourism - the root to displacement in Sweden? Doctoral Dissertation, Department of Social and Economic Geography, UMEA University, Sweden.

Mazón, T.; Aledo, A. (2005). El dilemma del Turismo residencial: Turismo y desarollo inmobiliario? Turismo residencial y cambio social: nuevas perspectives teóricas y empíricas. Alicante, CAM, Obras Sociales / FRAX / Universidade de Alicante, 1-30.

Mtur. Ministério do Turismo (2015). Diagnóstico e Plano Estratégico de Estatísticas Turísticas Nacionais (SDP No 06/2013) - Relatório 10-Diagnóstico para Colaboração com o IBGE em outras áreas. Versão Final 3a Versão, 30 de novembro de 2015. Disponível em: http://www.dadosefatos.turismo.gov.br/images/pdf/Plano nacional/R10 Avaliacao das pesquisas IBGE relacionadas ACTs.pdf. Acessado em janeiro de 2017.

Mtur. Ministério do Turismo (2015a). Portaria No 144 - Estabelece a categorização dos municípios pertencentes às regiões turísticas do Mapa do Turismo Brasileiro, definido por meio da Portaria Mtur nro 313, de 3 de dezembro de 2013 e dá outras providências. Brasília: Ministério do Turismo, 27 de agosto de 2015. Disponível em http://www.turismo.gov.br/legislacao/?p=822 Acessado em Março de 2016.

Muller, D. K.; Hall, M. e Keen, D. (2004). Second Home tourism impact, planning and management. Tourism, mobility and second homes - between elite landscape and common ground. Edited by Michael Hall and Dieter K. Muller, Frankfurt Lodge, 15-34.

Paris, C. (2006). Multiple homes, dwelling \& hypermobility \& emergent transnational second home ownership. Workshop 24. ENHR Conference - Housing in a expanding Europe: theory, policy, participation and implementation, Lyublyana, Slovenia.

Pereira, A.Q. (2014). A urbanização vai à praia: vilegiatura marítima e metrópole no Nordeste do Brasil. Fortaleza, Edições UFC.

Petterson, R. (1999). Foreign second home purchases - the case of Northern Sweden - 1990-1996. Working Paper, 14, Centre for Regional Science.
PR. Governo do Estado do Paraná - CEPATUR. (2016). Paraná Turístico 2026: Pacto para um destino inteligente. Curitiba.

Raffestin, C. (2009). A produção das estruturas territoriais e sua representação. Saquet, M. A.; Sposito, E. S. (orgs.). Territórios e territorialidades - teorias, processos e conflitos. São Paulo, Editora Expressão Popular.

RS. Governo do Rio Grande do Sul - Departamento de Desenvolvimento do Turismo. (2014). Análises Setoriais do Observatório do Turismo do Rio Grande do Sul, 1․ Edição, Porto Alegre.

Santos, M. (2006). A Natureza do Espaço - técnica e tempo, razão e emoção. São Paulo, Editora da Universidade de São Paulo.

Sayão, T.J. (2012). O despertar da fruição: a paisagem da Ilha de Santa Catarina vista através da literatura regionalista. Revista Espacialidades [online], 5(4), 150176.

Schossler, J. C.(2010). "As nossas praias": os primórdios da vilegiatura marítima no Rio Grande do Sul (1900-1950). Dissertação de Mestrado, Programa de Pós-Graduação em História da Faculdade de Filosofia e Ciências Humanas da Pontifícia Universidade Católica do Rio Grande do Sul, Porto Alegre.

SC. Governo do Estado de Santa Catarina - Conselho Estadual de Turismo do Estado de Santa Catarina. (2010). Plano de Marketing de Santa Catarina 2020 Plano Catarina, Joinville.

Silva, A.F.C.; FERREIRA, A.L. (2012). Imobiliário-turístico no litoral nordestino: investimentos estrangeiros e impactos locais nas praias potiguares. FONSECA, M.A.P Segunda residência, lazer e turismo. Natal: EUFRN, 127-153.

Sena, M.F.A.; Queiroz, O.T.M.M. (2006). Impactos ambientais e sócio-culturais do turismo de segunda residência: o caso de Ponta da Tulha, Ilhéus, Ba. Caderno Virtual de Turismo, 6 (4), 94-106.

Sette, I. R.; Tomazzoni, E. L. (2017). Os desafios, as limitações e as perspectivas do modelo do Índice de Competitividade Turística no contexto da política nacional de turismo brasileira. Revista Turismo - Visão e Ação, 19 (2), $292-318$.

Severino, A.J. (2013). Metodologia do trabalho científico. São Paulo, Cortez. 
Vágner, J.; Fialová, D. (2011). Impacts of second home tourism on shaping regional identity in the regions with significant recreational function. Book of proceedings Vol. 1 - International Conference on Tourism \& management studies, Algarve, Portugal.

Zuanazzi, P.T. (2016). Estimativas para a população flutuante do litoral norte do Rio Grande do Sul. Porto Alegre: FEE, 28p.
Informações dos autores

\section{Cinthia Sena Abrahão}

Universidade Federal do Paraná, Matinhos, PR, Brasil. E-mail: cisena01@gmail.com

\section{Edegar Luis Tomazzoni}

Universidade de São Paulo, São Paulo, SP, Brasil .

E-mail: eltomazzoni@usp.br 